\title{
ER-Mitochondria Crosstalk during Cerebral Ischemia: Molecular Chaperones and ER-Mitochondrial Calcium Transfer
}

\author{
Yi-Bing Ouyang and Rona G. Giffard \\ Department of Anesthesia, Stanford University School of Medicine, Stanford, CA 94305-5117, USA \\ Correspondence should be addressed to Yi-Bing Ouyang, ybouyang@stanford.edu
}

Received 1 December 2011; Accepted 12 January 2012

Academic Editor: Mariusz R. Wieckowski

Copyright ( $) 2012$ Y.-B. Ouyang and R. G. Giffard. This is an open access article distributed under the Creative Commons Attribution License, which permits unrestricted use, distribution, and reproduction in any medium, provided the original work is properly cited.

\begin{abstract}
It is commonly believed that sustained elevations in the mitochondrial matrix $\mathrm{Ca}^{2+}$ concentration are a major feature of the intracellular cascade of lethal events during cerebral ischemia. The physical association between the endoplasmic reticulum (ER) and mitochondria, known as the mitochondria-associated ER membrane (MAM), enables highly efficient transmission of Ca ${ }^{2+}$ from the ER to mitochondria under both physiological and pathological conditions. Molecular chaperones are well known for their protective effects during cerebral ischemia. It has been demonstrated recently that many molecular chaperones coexist with MAM and regulate the MAM and thus $\mathrm{Ca}^{2+}$ concentration inside mitochondria. Here, we review recent research on cerebral ischemia and MAM, with a focus on molecular chaperones and ER-mitochondrial calcium transfer.
\end{abstract}

\section{Introduction}

Stroke is one of the leading causes of death worldwide and a major cause of long-term disability [1]. Although many clinical trials have been completed in stroke patients, none of these have demonstrated protective efficacy except for thrombolysis [2, 3]. Suggested reasons for this failure include the complex interplay among multiple pathways (for review see [4-6]) including excitotoxicity, mitochondrial dysfunction, acidotoxicity, ionic imbalance, oxidative stress, and inflammation, which can all lead to cell death and irreversible tissue injury.

A generally accepted cell death pathway after cerebral ischemia is mitochondrial permeability transition (MPT) pore opening (Figure 1(a)). Ischemia leads to energy deprivation and loss of ion homeostasis. As the cells are unable to maintain a negative membrane potential, they depolarize, leading to the opening of voltage-gated calcium channels and release of excitatory amino acids into the extracellular space [7]. This cascade of events leads to a massive entry of calcium and this increase in free cytosolic calcium is transmitted to the matrix of mitochondria by $\mathrm{Ca}^{2+}$ channels and exchangers located on the inner mitochondrial membrane. Recently ER stress was found to be one of the effects of excitotoxicity, that is, exposure to toxic levels of excitatory neurotransmitters, with release of $\mathrm{Ca}^{2+}$ from the ER via both ryanodine receptors and IP3R, with release from inositol trisphosphate receptors (IP3Rs) leading to mitochondrial $\mathrm{Ca}^{2+}$ overload and activation of apoptosis [8]. Excessive increases in matrix $\mathrm{Ca}^{2+}$ alter the permeability of mitochondria and finally open the MPT pore [9], causing the release of cytochrome c [10] and other proapoptotic factors into the cytoplasm. The released cytochrome $c$ activates caspase-3, one of the executioner caspases to initiate cell death. Excessive accumulation of calcium in mitochondria is a key factor in the final outcome of the cascade leading to neural cell death (Figure 1(a)) [11].

Mitochondria can accumulate large amounts of calcium through a $\mathrm{Ca}^{2+}$-selective channel known as the mitochondrial $\mathrm{Ca}^{2+}$ uniporter (MCU) $[12,13]$. However, MCU has a relatively low $\mathrm{Ca}^{2+}$ affinity [14]. It is interesting that in response to cytosolic $\mathrm{Ca}^{2+}$ transients not exceeding concentrations of $1-3 \mu \mathrm{M}$, mitochondrial $\mathrm{Ca}^{2+}$ concentrations rise almost simultaneously to values above $10 \mu \mathrm{M}$ [15]. The existence of close contact points between the ER and mitochondria (the mitochondria-associated ER membrane, 


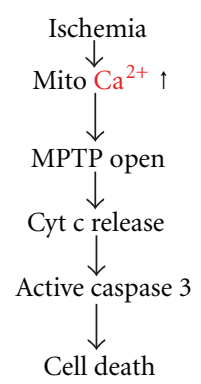

(a)

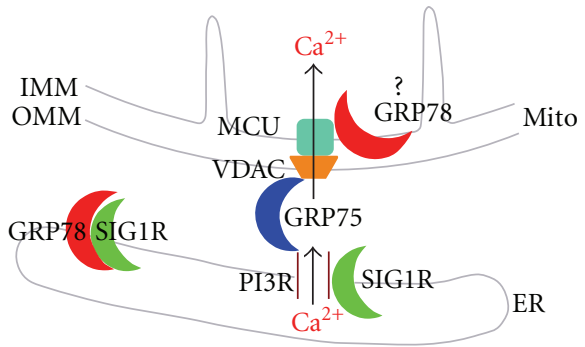

(b)
Figure 1: (a) Diagram of cerebral ischemia-induced cell death signaling cascade. (b) Chaperone machinery controls ER-mitochondria $\mathrm{Ca}^{2+}$ crosstalk at the MAM. Under normal, resting conditions, SIG1R chaperone forms a complex with GRP78 at the ER. Under stress such as ischemia, SIG1R dissociates from GRP78 and associates with IP3R3 at the MAM, and GRP78 translocates from ER to IMM. ER-mitochondria $\mathrm{Ca}^{2+}$ transfer controls cell survival or death decision. Cyt c: cytochrome c; ER: endoplasmic reticulum; GRP75: glucose-regulated protein 75; GRP78: glucoseregulated protein $78 \mathrm{kDa}$; IMM: inner mitochondrial membrane; IP3R: inositol trisphosphate receptor; MCU: mitochondrial $\mathrm{Ca}^{2+}$ uniporter; Mito: mitochondria; MPTP: mitochondrial permeability transition pore; OMM: outer mitochondrial membrane; SIG1R: sigma-1 receptor; VDAC: voltage-dependent anion channel.

MAM) is thought to provide a selective direct pathway for calcium from the ER to mitochondria. Upon cell stimulation, the release of high concentrations of $\mathrm{Ca}^{2+}$ at MAM leads to the formation of microdomains of high $\mathrm{Ca}^{2+}$ concentration that is crucial for efficient $\mathrm{Ca}^{2+}$ uptake by mitochondria $[16,17]$.

Molecular chaperones are a functionally related group of proteins that assist protein folding in cells and protect cells from injury after cerebral ischemia or other stress. It has been demonstrated recently that MAM coexists with many molecular chaperones [18]. The relationship between molecular chaperones and ER-mitochondrial calcium transfer after cerebral ischemia is an emerging research area and is the focus of this mini review.

\section{Cerebral Ischemic Models}

Animal models of ischemic stroke are used to study the basic pathophysiological processes and potential therapeutic interventions in this disease; the extension of knowledge gained from these animal models will lead to improvement of medical treatment for human ischemic stroke in the future. Focal cerebral ischemia by middle cerebral artery occlusion (MCAO) in rats or mice is the rodent model most immediately relevant to human stroke. Using this method, transient ischemia is achieved by inserting a suture into the left middle cerebral artery, temporarily blocking blood flow to the middle cerebral artery territory, and removing the suture to allow reperfusion after a duration of minutes to hours depending on the specific study $[9,19,20]$.
Glucose deprivation (GD) and combined oxygen-glucose deprivation (OGD) are common in vitro models of brain ischemia. Either cell cultures or slice cultures are subjected to medium lacking glucose, and in the case of OGD, also placed in a chamber with very low oxygen levels for a fixed period of time [19, 21-26], followed by restoration of oxygen and glucose to the medium to imitate reperfusion.

\section{Molecular Chaperones}

Molecular chaperones were originally defined as a functionally related group of proteins that assist protein folding in bacterial, plant, and animal cells. The heat shock proteins of the $70 \mathrm{kDa}$ molecular weight family (HSP70), including HSP72 (cytosol), GRP75/mortalin (mitochondria), and GRP78/BIP (endoplasmic reticulum; ER), are highly evolutionarily conserved and have been extensively studied. Studies, including those from our laboratory, show that all three of these HSP70 family members are protective in both in vivo and in vitro models of stroke [19, 27-32]. It has been a long-standing observation, as documented for HSP72 [3335] and GRP75 [36], that cells destined to die fail to produce heat shock proteins, while cells that survive make new heat shock proteins. We recently identified translational arrest of GRP78 due to microRNA181 in focal cerebral ischemia in the mouse [19]. Although Grp78 mRNA was induced following MCAO both in the core and outside the infarcted area, GRP78 protein was only induced in the penumbra, not within the area of infarction.

Recently a more complex, integrating role of these proteins has been recognized, that of stabilizing intracellular morphological and functional networks through proteinprotein interactions with numerous client proteins [37-39]. This chaperoning network concept is increasingly accepted as a basic regulatory mechanism in diverse cellular functions $[39,40]$. These networks allow the cell to change phenotype by releasing client proteins from chaperones allowing them to be activated, or in some cases released and degraded. These functional adjustments are rapid, do not require protein synthesis, and facilitate calibrated and integrated adaptation to changing conditions.

In addition to the new concept of the chaperone network, each individual chaperone has been found to have additional functions beyond that of functioning as a molecular chaperone. For example, GRP78 is traditionally considered to be a major endoplasmic reticulum chaperone as well as a master regulator of the unfolded protein response. Due to recent findings that significant amounts of GRP78 are present on the surface of cancer cells, it has emerged as an important regulator of tumor cell viability signaling, and cell surface GRP78 is now being used for therapeutic targeting [41]. In addition to GRP78, the ER calciumbinding protein calreticulin has also been shown to traffic to the plasma membrane and be involved in regulation of cell death $[42,43]$. GRP78 plays a critical role in physiologic and pathologic stress [44], including developmental and neurological disorders [45]. As a multifunctional receptor on the cell surface [46], GRP78 may be associated with the AKT and ERK signaling pathways [47]. Because of its multiple 
locations and functions, GRP78 may play a central role in the chaperone network. HSP72 also protects brain by regulating distinct pathways of apoptosis and inflammation which both contribute to outcome after cerebral ischemia (for review see [48]). Other ER proteins also participate in cell death regulation, and function outside the ER.

\section{The Mitochondria-Associated ER Membrane (MAM)}

Although the association of endoplasmic reticulum (ER) with mitochondria was first observed in the 1960s by several independent groups $[49,50]$, morphological evidence for the physical association or interaction between the ER and mitochondria first emerged in the early 1990s. Such contact has since been observed in mitochondria in many types of cell $[51,52]$. Structural and functional interactions of mitochondria with the ER have been demonstrated for rat brain [53]. The close contacts through which ER communicates with mitochondria are referred to as MAM [54]. The distance between the ER and the outer mitochondrial membrane (OMM) was originally estimated to be approximately $100 \mathrm{~nm}[51,52]$. However, a more recent study using electron tomography showed that the minimum distance is even less, $10 \mathrm{~nm}$ at the smooth ER and $25 \mathrm{~nm}$ at the rough ER [55]. Actually the spacing between the ER and mitochondria changes with different cell physiological and pathological conditions $[56,57]$ and artificial modification of this contact can lead to ER stress [55].

Numerous proteins have recently been proposed to participate in the interaction and communication between the mitochondria and the ER, highlighting the emerging role of this region in bioenergetics, cell survival, and cell death $[58,59]$. One important structure is the IP3R on the ER and the voltage-dependent anion channel (VDAC) on the OMM which are now thought to be physically coupled through the chaperone Grp75/mortalin (Figure 1(b)) [60]. The sigma1 receptor (SIG1R) chaperone is enriched in the MAM fraction [61-64] and recruits GRP78. In addition, other $\mathrm{Ca}^{2+}$-binding ER resident chaperones have been found in the MAM fraction, for example, calnexin (CNX), calreticulin, and ERp44 [65-67]. The multifunctional cytosolic sorting protein PACS-2 is another protein that has been found in the MAM fraction [68]. This fraction can also contain adenine nucleotide translocase (ANT) and cyclophylin D, the components of mitochondrial contact sites with similar composition to the mitochondrial permeability transition pore (MPTP). Such close apposition of the MPTP to the ER can sensitize mitochondria to $\mathrm{Ca}^{2+}$ signals [69]. Recently, the mitochondrial GTPase mitofusin 2 has been shown to be enriched in MAM as well as localized on the ER, where it interacts with mitofusins on mitochondria to form interorganellar bridges [70].

MAM can be isolated from tissues and cells to investigate the mechanisms and functions involved $[60,71]$. Wieckowski et al. provided detailed protocols in 2009 in Nature Protocols [71]. Briefly the procedure consists of two steps: a crude mitochondrial fraction is isolated from tissue or cells by differential centrifugation, and the crude mitochondria are fractionated to the pure mitochondria and MAM fraction by Percoll density gradient.

\section{5. $\mathrm{Ca}^{2+}$ Signaling at the MAM during Apoptosis}

It is commonly accepted that the main structure responsible for ER-mitochondrial calcium transfer at the MAM is composed of the IP3R on the ER, VDAC on the OMM and MCU on the IMM (Figure $1(\mathrm{~b})$ ). $\mathrm{Ca}^{2+}$ released upon activation of the IP3R at the ER is taken up into mitochondria via VDAC and then $\mathrm{MCU}[72,73]$.

A major function of MAM is the control of $\mathrm{Ca}^{2+}$ signaling between ER and mitochondria, a central topic of major interest both in normal physiology and pathophysiology. This second messenger has been proposed to have multiple roles in modulating intracellular events including bioenergetics and autophagy. Constitutive calcium release via the IP3R was found to be essential for maintaining normal bioenergetics and suppressing autophagy in conditions of ready nutrient availability [74]. In contrast during ER stress, $\mathrm{Ca}^{2+}$ increase seems to be required for triggering autophagy [75], though calcium-independent routes to induce autophagy involving interaction of IP3R with Beclin have also been reported [76], and lack of $\mathrm{Ca}^{2+}$ release via the IP3R can also induce autophagy [74]. Thus the role of calcium is complex, and induction of autophagy reflects combined input from $\mathrm{Ca}^{2+}$ dependent and independent pathways (see recent review [77]). Under prolonged ER stress conditions, as happens in the ischemic core after cerebral ischemia, a slow but sustained increase in mitochondrial matrix free $\left[\mathrm{Ca}^{2+}\right]$ can occur, which can reach a critical threshold to trigger the opening of MPTP and initiate the apoptotic cascade (Figure 1(a)). Some studies indicate that the induction of apoptosis by ER stress has a mandatory mitochondrial component, further highlighting the intimate connection between these two organelles [78].

The ER can play an important role in regulating apoptosis by adjusting the load of $\mathrm{Ca}^{2+}$ imposed upon the mitochondrion. Previous studies have shown that the reduction in the $\mathrm{Ca}^{2+}$ amount that can be released from ER to mitochondria decreases the probability of $\mathrm{Ca}^{2+}$-dependent apoptosis. On the other hand, conditions that increase $\mathrm{ER} \mathrm{Ca}^{2+}$ storage have the opposite effect on $\mathrm{Ca}^{2+}$-dependent apoptosis [79-82]. It has been demonstrated that overexpression of the antiapoptotic protein BCL2 can influence the distribution of $\mathrm{Ca}^{2+}$ within the ER/mitochondrial complex. Knockout of the proapoptotic proteins BAX and BAK reduced the resting concentration of $\mathrm{ER} \mathrm{Ca}^{2+}$ decreasing the uptake of $\mathrm{Ca}^{2+}$ by mitochondria after $\mathrm{Ca}^{2+}$ release from the ER [81]. The active form of the antiapoptotic protein AKT results in reduced ER $\mathrm{Ca}^{2+}$ release, and diminished cellular sensitivity to $\mathrm{Ca}^{2+}$ mediated apoptotic stimuli $[79,82]$. Antiapoptotic proteins BCL2 and AKT affect ER calcium homeostasis by differential mechanisms: BCL2 overexpression increases the $\mathrm{Ca}^{2+}$ leak from the ER, while AKT hyperactivation induces a decrease in $\mathrm{ER} \mathrm{Ca}^{2+}$ release, probably through phosphorylation of the IP3R $[58,80]$. 

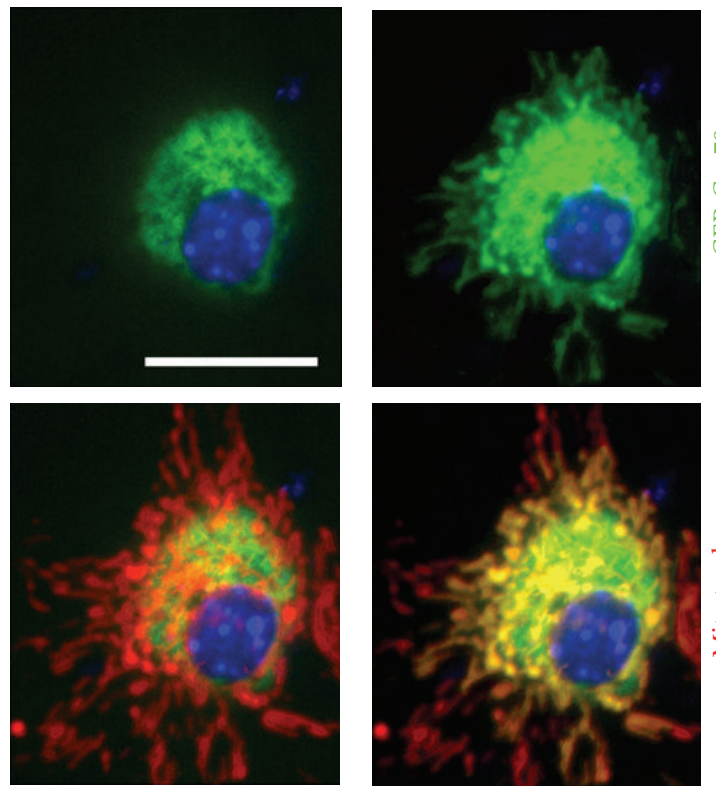

0 hr GD

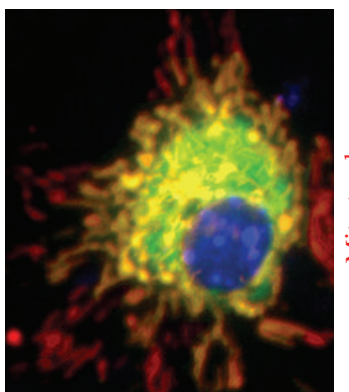

$1 \mathrm{hr}$ GD

(a)

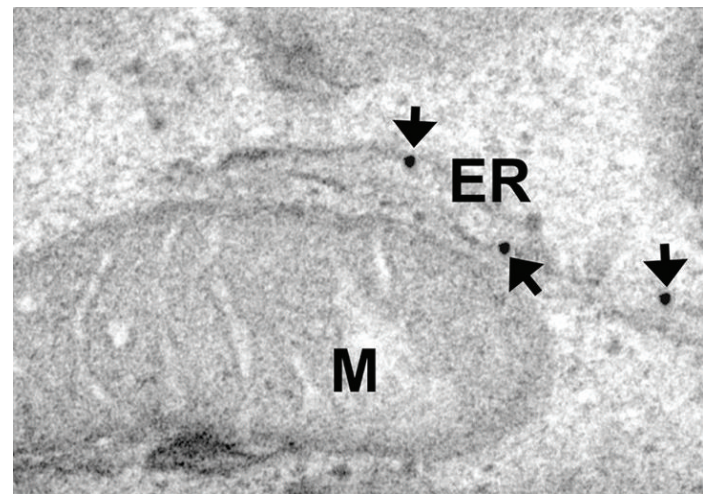

Control
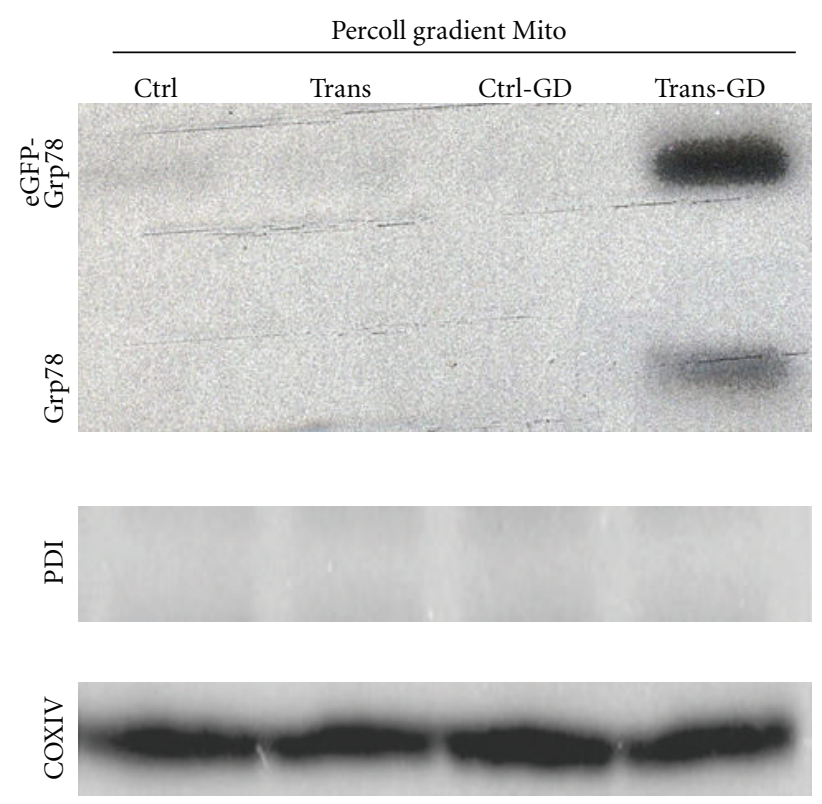

(b)

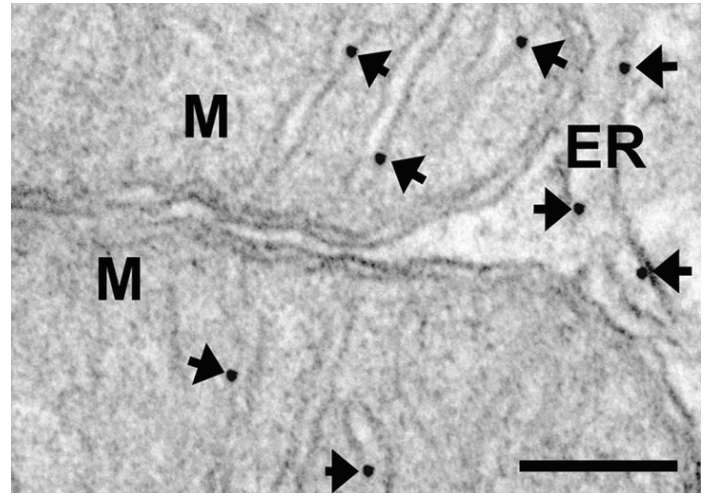

Transfected

(c)

FIGURE 2: GRP78 retargets to mitochondria with glucose deprivation (GD). (a) Fluorescence photomicrographs were taken before and after $1 \mathrm{hr}$ GD. Under normal conditions, the green fluorescence in eGFP-Grp78 transfected cells shows the normal perinuclear ER localization. After $1 \mathrm{hr}$ GD this changes to a diffuse cytoplasmic pattern overlapping with the mitochondrial distribution visualized by partial overlap with Mito-tracker (red) fluorescence. Overlap is yellow. (b) After $3 \mathrm{hr}$ GD, mitochondria were purified and analyzed by Western blotting using antibodies against GRP78, PDI (an ER-specific marker), or COXIV (a mitochondrial marker). The purified mitochondria do not show contamination with ER marker PDI but do have GRP78. Ctrl: control. Trans: transfected. (c) Submitochondrial localization of GRP78 in control and GD-stressed cells by immunoelectron microscopy. Arrows point to the localization of GRP78. The gold particles were associated exclusively with ER membrane in control cells (left panel). In contrast, immune-EM staining shows GRP78 within mitochondria from $3 \mathrm{hr}$ GD-stressed cells, demonstrating significant mitochondrial labeling, with grains mainly decorating the inner mitochondrial membrane (right panel). M, mitochondrion. Scale bars, $100 \mathrm{~nm}$.

\section{Molecular Chaperones Regulate MAM}

Some important chaperones are enriched in MAM and may play a key role in regulating $\mathrm{Ca}^{2+}$ signaling between ER and mitochondria. It was found that the mitochondrial chaperone GRP75 regulates IP3R-mediated mitochondrial $\mathrm{Ca}^{2+}$ signaling [60]. It was demonstrated that isoform 1 of VDAC is physically linked to the $\mathrm{ER} \mathrm{Ca}^{2+}$-release channel IP3R through GRP75, highlighting chaperone-mediated conformational coupling between the IP3R and the mitochondrial
$\mathrm{Ca}^{2+}$ uptake machinery (Figure $\left.1(\mathrm{~b})\right)$. We have found that overexpression of GRP75 improved mitochondrial function after in vivo and in vitro cerebral ischemia $[31,83]$.

ER protein SIG1R, implicated in neuroprotection, carcinogenesis, and neuroplasticity, is a $\mathrm{Ca}^{2+}$-sensitive and ligand-operated receptor chaperone at the MAM [62]. Normally, SIG1R forms a complex at the MAM with another ER chaperone GRP78/BiP (Figure 1(b)). Upon ER $\mathrm{Ca}^{2+}$ depletion or after ligand stimulation, SIG1R can dissociate from GRP78 and begin to chaperone conformationally unstable 
IP3R (Figure 1(b)) to enhance $\mathrm{Ca}^{2+}$ signaling from the ER into mitochondria to increase the production of ATP in the cell through the tricarboxylic acid cycle in the mitochondria [74]. If stimulated by high concentrations of agonists or impacted by extreme ER stress, SIG1Rs translocate from the MAM to the plasma membrane to bind various ion channels, receptors, or kinases $[63,84-86]$. An increase of SIG1R in cells counteracts ER stress, whereas decreased levels enhance apoptosis.

Recent evidence [41] indicates that GRP78, like SIG1R, may emerge as a novel interorganelle signaling modulator. As a multifunctional receptor on the cell surface after stress [46], GRP78 may be associated with many signaling pathways [47]. However, until now there has been no detailed research on the importance of GRP78 in MAM except as a binding partner of SIG1R (Figure 1(b)). GRP78 has been found to be one of the VDAC interactors (Table 1 in [60]) together with GRP75, although the authors of the paper never discuss it in the text [60]. We recently found that overexpressing GRP78 preserves respiratory activity and mitochondrial membrane potential, reduces free radical production, reduces mitochondria $\mathrm{Ca}^{2+}$ overload, and increases $\mathrm{Ca}^{2+}$ uptake capacity in isolated mitochondria after stress [22]. In order to follow GRP78 directly in response to ischemia-like stress, we created a fusion protein consisting of green fluorescent protein (eGFP) fused between the GRP78 N-terminal 18 amino acid ER signal peptide and the remainder of GRP78. We found that eGFP-GRP78 retargets to mitochondria within a short period of GD by fluorescence and immunoelectron microscopy (IEM) as well as Western blotting (Figure 2). The mitochondrial location of GRP78 is mainly on the inner membrane of mitochondria by IEM (Figure 2(c)). A prior report in 9L tumor cells has demonstrated relocalization of GRP78 to mitochondria after induction of ER stress by thapsigargin [87]. As in the case of translocation to the cell surface, cytoplasm, and nucleus after stress [41], the molecular mechanism underlying GRP78 translocation to mitochondria has not yet been elucidated.

The mitochondrial $\mathrm{Ca}^{2+}$ uniporter is the primary influx pathway for $\mathrm{Ca}^{2+}$ into respiring mitochondria, and hence is a key regulator of mitochondrial $\mathrm{Ca}^{2+}$. Although the uniporter's biophysical properties have been studied extensively, its molecular composition remained elusive for more than 50 years. A very recent report has identified a $40-\mathrm{kDa}$ protein which fulfills the requirements for being the long sought mitochondrial calcium uniporter [72]. Overexpression of MCU alone in one report did not give rise to a marked gain of $\mathrm{Ca}^{2+}$ uptake in HeLa cells indicating that additional components or chaperones may be limiting in some settings [88], though other investigators did observe increased $\mathrm{Ca}^{2+}$ with overexpression [72]. The MCU is thought to function as part of a complex including at least MICU1 [89]. Considering the fact that overexpressing GRP78 not only reduces mitochondria $\mathrm{Ca}^{2+}$ overload in intact cells, but also increases $\mathrm{Ca}^{2+}$ uptake capacity in isolated mitochondria [22], it is possible that translocated GRP78 interacts with the uniporter in some way on the IMM and regulates the mitochondrial $\mathrm{Ca}^{2+}$. Future validation of the hypothesis depends on further development of molecular approaches to confirm this property of MCU and its relationship with GRP78.

In summary these findings together support a new emerging picture: chaperone machineries at both the ER and mitochondrion orchestrate the regulation of $\mathrm{Ca}^{2+}$ signaling between these two organelles and control bioenergetics, cell survival, and cell death decisions. In the brain, ER calcium release has been found to directly contribute to excitotoxicity, a neuronal death mechanism important both in acute and chronic neurodegenerative diseases. Better understanding the roles of chaperones and $\mathrm{Ca}^{2+}$ handling in vivo should in the future provide new therapeutic strategies to protect brain cells during ischemia.

\section{Acknowledgments}

This work was supported in part by NIH grants NS053898 and GM49831 to RGG. The authors would like to thank William Magruder for help preparing the paper. The authors have no conflicting financial interests.

\section{References}

[1] D. Lloyd-Jones, R. J. Adams, T. M. Brown et al., "Executive summary: heart disease and stroke statistics-2010 update: a report from the american heart association," Circulation, vol. 121, no. 7, pp. e46-e215, 2010.

[2] J. O. Blakeley and R. H. Llinas, "Thrombolytic therapy for acute ischemic stroke," Journal of the Neurological Sciences, vol. 261, no. 1-2, pp. 55-62, 2007.

[3] V. J. Marder, R. Jahan, T. Gruber, A. Goyal, and V. Arora, "Thrombolysis with plasmin: implications for stroke treatment," Stroke, vol. 41, no. 10, pp. S45-S49, 2010.

[4] B. K. Siesjo, E. Elmer, S. Janelidze et al., "Role and mechanisms of secondary mitochondrial failure," Acta Neurochirurgica, Supplement, vol. 1999, supplement 73, pp. 7-13, 1999.

[5] B. K. Siesjo, Y. B. Ouyang, T. Kristian et al., "Role of mitochondria in immediate and delayed reperfusion damage," in Maturation Phenomenon in Cerebral Ischemia III, U. Ito, Ed., Springer Verlag, Berlin, Germany, 1999.

[6] Y. B. Ouyang, T. Kristian, P. A. Li, and B. K. Siesjo, "Mitochondria, free radicals, and ischemic brain damage," in Pharmacology of Cerebral Ischemia, J. Krieglstein, Ed., Wissenschaftliche Verlagsgesellschaft, Stuttgart, Germany, 1998.

[7] T. Kristián, Y. Ouyang, and B. K. Siesjö, "Calcium-induced neuronal cell death in vivo and in vitro: are the pathophysiologic mechanisms different?" Advances in Neurology, vol. 71, pp. 107-118, 1996.

[8] A. Ruiz, C. Matute, and E. Alberdi, "Endoplasmic reticulum $\mathrm{Ca}^{2+}$ release through ryanodine and IP3 receptors contributes to neuronal excitotoxicity," Cell Calcium, vol. 46, no. 4, pp. 273-281, 2009.

[9] Y. B. Ouyang, S. Kuroda, T. Kristián, and B. K. Siesjö, "Release of mitochondrial aspartate aminotransferase (mAST) following transient focal cerebral ischemia suggests the opening of a mitochondrial permeability transition pore," Neuroscience Research Communications, vol. 20, no. 3, pp. 167-173, 1997.

[10] Y.-B. Ouyang, Y. Tan, M. Comb et al., "Survival- and deathpromoting events after transient cerebral ischemia(colon): phosphorylation of Akt, release of cytochrome C, and activation of caspase- like proteases," Journal of Cerebral Blood Flow and Metabolism, vol. 19, no. 10, pp. 1126-1135, 1999. 
[11] Y. Gouriou, N. Demaurex, P. Bijlenga, and U. de Marchi, "Mitochondrial calcium handling during ischemia-induced cell death in neurons," Biochimie, vol. 93, no. 12, pp. 20602067, 2011.

[12] Y. Kirichok, G. Krapivinsky, and D. E. Clapham, "The mitochondrial calcium uniporter is a highly selective ion channel," Nature, vol. 427, no. 6972, pp. 360-364, 2004.

[13] D. G. Nicholls and S. L. Budd, "Mitochondria and neuronal survival," Physiological Reviews, vol. 80, no. 1, pp. 315-360, 2000.

[14] P. Bernardi, "Mitochondrial transport of cations: channels, exchangers, and permeability transition," Physiological Reviews, vol. 79, no. 4, pp. 1127-1155, 1999.

[15] R. Rizzuto and T. Pozzan, "Microdomains of intracellular $\mathrm{Ca}^{2+}$ : molecular determinants and functional consequences," Physiological Reviews, vol. 86, no. 1, pp. 369-408, 2006.

[16] R. Rizzuto, M. Brini, M. Murgia, and T. Pozzan, "Microdomains with high $\mathrm{Ca}^{2+}$ close to IP3-sensitive channels that are sensed by neighboring mitochondria," Science, vol. 262, no. 5134, pp. 744-747, 1993.

[17] R. Rizzuto, P. Pinton, W. Carrington et al., "Close contacts with the endoplasmic reticulum as determinants of mitochondrial $\mathrm{Ca}^{2+}$ responses," Science, vol. 280, no. 5370, pp. $1763-$ 1766, 1998.

[18] T. Hayashi, R. Rizzuto, G. Hajnoczky, and T. P. Su, "MAM: more than just a housekeeper," Trends in Cell Biology, vol. 19, no. 2, pp. 81-88, 2009.

[19] Y.-B. Ouyang, Y. Lu, S. Yue et al., "MiR-181 regulates GRP78 and influences outcome from cerebral ischemia in vitro and in vivo," Neurobiology of Disease, vol. 45, no. 1, pp. 555-563, 2012.

[20] G. X. Wang, G. R. Li, Y. D. Wang, T. S. Yang, and Y. B. Ouyang, "Characterization of neuronal cell death in normal and diabetic rats following exprimental focal cerebral ischemia," Life Sciences, vol. 69, no. 23, pp. 2801-2810, 2001.

[21] Y. B. Ouyang, L. A. Voloboueva, L. J. Xu, and R. G. Giffard, "Selective dysfunction of hippocampal CA1 astrocytes contributes to delayed neuronal damage after transient forebrain ischemia," Journal of Neuroscience, vol. 27, no. 16, pp. 42534260, 2007.

[22] Y. B. Ouyang, L. J. Xu, J. F. Emery, A. S. Lee, and R. G. Giffard, "Overexpressing GRP78 influences $\mathrm{Ca}^{2+}$ handling and function of mitochondria in astrocytes after ischemia-like stress," Mitochondrion, 2010.

[23] Y. B. Ouyang, L. J. Xu, Y. J. Sun, and R. G. Giffard, "Overexpression of inducible heat shock protein 70 and its mutants in astrocytes is associated with maintenance of mitochondrial physiology during glucose deprivation stress," Cell Stress and Chaperones, vol. 11, no. 2, Article ID csac. 2006.CSC-182R, pp. 180-186, 2006.

[24] Y. B. Ouyang, S. G. Carriedo, and R. G. Giffard, "Effect of $\mathrm{Bcl}-\mathrm{xL}$ overexpression on reactive oxygen species, intracellular calcium, and mitochondrial membrane potential following injury in astrocytes," Free Radical Biology and Medicine, vol. 33, no. 4, pp. 544-551, 2002.

[25] Y. B. Ouyang and R. G. Giffard, "Bcl-xL maintains mitochondrial function in murine astrocytes deprived of glucose," Journal of Cerebral Blood Flow and Metabolism, vol. 23, no. 3, pp. 275-279, 2003.

[26] Y. B. Ouyang, L. Xu, and R. G. Giffard, "Geldanamycin treatment reduces delayed CA1 damage in mouse hippocampal organotypic cultures subjected to oxygen glucose deprivation," Neuroscience Letters, vol. 380, no. 3, pp. 229-233, 2005.
[27] B. Hoehn, T. M. Ringer, L. Xu et al., "Overexpression of HSP72 after induction of experimental stroke protects neurons from ischemic damage," Journal of Cerebral Blood Flow and Metabolism, vol. 21, no. 11, pp. 1303-1309, 2001.

[28] T. Kudo, S. Kanemoto, H. Hara et al., "A molecular chaperone inducer protects neurons from ER stress," Cell Death and Differentiation, vol. 15, no. 2, pp. 364-375, 2008.

[29] Y. Oida, H. Izuta, A. Oyagi et al., "Induction of BiP, an ER-resident protein, prevents the neuronal death induced by transient forebrain ischemia in gerbil," Brain Research C, vol. 1208, pp. 217-224, 2008.

[30] S. Rajdev, K. Hara, Y. Kokubo et al., "Mice overexpressing rat heat shock protein 70 are protected against cerebral infarction," Annals of Neurology, vol. 47, no. 6, pp. 782-791, 2000.

[31] L. Xu, L. A. Voloboueva, Y. Ouyang, J. F. Emery, and R. G. Giffard, "Overexpression of mitochondrial Hsp70/Hsp75 in rat brain protects mitochondria, reduces oxidative stress, and protects from focal ischemia," Journal of Cerebral Blood Flow and Metabolism, vol. 29, no. 2, pp. 365-374, 2009.

[32] L. Xu, X. Xiong, Y. Ouyang, G. Barreto, and R. Giffard, "Heat shock protein 72 (Hsp72) improves long term recovery after focal cerebral ischemia in mice," Neuroscience Letters, vol. 488, no. 3, pp. 279-282, 2011.

[33] H. Kinouchi, F. R. Sharp, M. P. Hill, J. Koistinaho, S. M. Sagar, and P. H. Chan, "Induction of 70-kDa heat shock protein and hsp70 mRNA following transient focal cerebral ischemia in the rat," Journal of Cerebral Blood Flow and Metabolism, vol. 13, no. 1, pp. 105-115, 1993.

[34] H. Kinouchi, F. R. Sharp, J. Koistinaho, K. Hicks, H. Kamii, and P. H. Chan, "Induction of heat shock hsp70 mRNA and HSP70 kDa protein in neurons in the "penumbra" following focal cerebral ischemia in the rat," Brain Research, vol. 619, no. 1-2, pp. 334-338, 1993.

[35] K. Vass, W. J. Welch, and T. S. Nowak, "Localization of 70-kDa stress protein induction in gerbil brain after ischemia," Acta Neuropathologica, vol. 77, no. 2, pp. 128-135, 1988.

[36] S. M. Massa, F. M. Longo, J. Zuo, S. Wang, J. Chen, and F. R. Sharp, "Cloning of rat grp75, an hsp70-family member, and its expression in normal and ischemic brain," Journal of Neuroscience Research, vol. 40, no. 6, pp. 807-819, 1995.

[37] A. L. Barabási and Z. N. Oltvai, "Network biology: understanding the cell's functional organization," Nature Reviews Genetics, vol. 5, no. 2, pp. 101-113, 2004.

[38] P. Csermely, "Strong links are important, but weak links stabilize them," Trends in Biochemical Sciences, vol. 29, no. 7, pp. 331-334, 2004.

[39] C. Soti, C. Pál, B. Papp, and P. Csermely, "Molecular chaperones as regulatory elements of cellular networks," Current Opinion in Cell Biology, vol. 17, no. 2, pp. 210-215, 2005.

[40] P. Csermely and L. Vigh, Eds., Molecular Aspects of the Stress Reponse: Chaperones, Membranes and Networks, Springer Science, New York, NY, USA, 2007.

[41] M. Ni, Y. Zhang, and A. S. Lee, "Beyond the endoplasmic reticulum: a typical GRP78 in cell viability, signalling and therapeutic targeting," Biochemical Journal, vol. 434, no. 2, pp. 181-188, 2011.

[42] T. Panaretakis, O. Kepp, U. Brockmeier et al., "Mechanisms of pre-apoptotic calreticulin exposure in immunogenic cell death," EMBO Journal, vol. 28, no. 5, pp. 578-590, 2009.

[43] R. Tufi, T. Panaretakis, K. Bianchi et al., "Reduction of endoplasmic reticulum $\mathrm{Ca}^{2+}$ levels favors plasma membrane surface exposure of calreticulin," Cell Death and Differentiation, vol. 15, no. 2, pp. 274-282, 2008. 
[44] K. T. Pfaffenbach and A. S. Lee, "The critical role of GRP78 in physiologic and pathologic stress," Current Opinion in Cell Biology, 2010.

[45] M. Wang, S. Wey, Y. Zhang, R. Ye, and A. S. Lee, "Role of the unfolded protein response regulator GRP78/BiP in development, cancer, and neurological disorders," Antioxidants and Redox Signaling, vol. 11, no. 9, pp. 2307-2316, 2009.

[46] M. Gonzalez-Gronow, M. A. Selim, J. Papalas, and S. V. Pizzo, "GRP78: a multifunctional receptor on the cell surface," Antioxidants and Redox Signaling, vol. 11, no. 9, pp. 22992306, 2009.

[47] L. H. Zhang, X. L. Yang, X. Zhang, J. X. Cheng, and W. Zhang, "Association of elevated GRP78 expression with increased astrocytoma malignancy via Akt and ERK pathways," Brain Research, 2010.

[48] R. G. Giffard, R. Q. Han, J. F. Emery, M. Duan, and J. F. Pittet, "Regulation of apoptotic and inflammatory cell signaling in cerebral ischemia: the complex roles of heat shock protein 70," Anesthesiology, vol. 109, no. 2, pp. 339-348, 2008.

[49] D. E. Copeland and A. J. Dalton, "An association between mitochondria and the endoplasmic reticulum in cells of the pseudobranch gland of a teleost," The Journal of biophysical and biochemical cytology, vol. 5, no. 3, pp. 393-396, 1959.

[50] J. R. Ruby, R. F. Dyer, and R. G. Skalko, "Continuities between mitochondria and endoplasmic reticulum in the mammalian ovary," Zeitschrift für Zellforschung und Mikroskopische Anatomie, vol. 97, no. 1, pp. 30-37, 1969.

[51] C. A. Mannella, M. Marko, P. Penczek, D. Barnard, and J. Frank, "The internal compartmentation of rat-liver mitochondria: tomographic study using the high-voltage transmission electron microscope," Microscopy Research and Technique, vol. 27, no. 4, pp. 278-283, 1994.

[52] B. J. Soltys and R. S. Gupta, "Interrelationships of endoplasmic reticulum, mitochondria, intermediate filaments, and microtubules - a quadruple fluorescence labeling study," Biochemistry and Cell Biology, vol. 70, no. 10-11, pp. 11741186, 1992.

[53] O. Camici and L. Corazzi, "Phosphatidylserine translocation into brain mitochondria: involvement of a fusogenic protein associated with mitochondrial membranes," Molecular and Cellular Biochemistry, vol. 175, no. 1-2, pp. 71-80, 1997.

[54] J. E. Vance, "Phospholipid synthesis in a membrane fraction associated with mitochondria," Journal of Biological Chemistry, vol. 265, no. 13, pp. 7248-7256, 1990.

[55] G. Csordás, C. Renken, P. Várnai et al., "Structural and functional features and significance of the physical linkage between ER and mitochondria," Journal of Cell Biology, vol. 174, no. 7, pp. 915-921, 2006.

[56] R. Bravo, J. M. Vicencio, V. Parra et al., "Increased ERmitochondrial coupling promotes mitochondrial respiration and bioenergetics during early phases of ER stress," Journal of Cell Science, vol. 124, no. 13, pp. 2143-2152, 2011.

[57] M. Chami, B. Oulès, G. Szabadkai, R. Tacine, R. Rizzuto, and P. Paterlini-Bréchot, "Role of SERCA1 Truncated Isoform in the Proapoptotic Calcium Transfer from ER to Mitochondria during ER Stress," Molecular Cell, vol. 32, no. 5, pp. 641-651, 2008.

[58] C. Giorgi, D. de Stefani, A. Bononi, R. Rizzuto, and P. Pinton, "Structural and functional link between the mitochondrial network and the endoplasmic reticulum," International Journal of Biochemistry and Cell Biology, vol. 41, no. 10, pp. 1817 1827, 2009.

[59] M. Lebiedzinska, G. Szabadkai, A. W. E. Jones, J. Duszynski, and M. R. Wieckowski, "Interactions between the endoplasmic reticulum, mitochondria, plasma membrane and other subcellular organelles," International Journal of Biochemistry and Cell Biology, vol. 41, no. 10, pp. 1805-1816, 2009.

[60] G. Szabadkai, K. Bianchi, P. Várnai et al., "Chaperonemediated coupling of endoplasmic reticulum and mitochondrial Ca ${ }^{2+}$ channels," Journal of Cell Biology, vol. 175, no. 6, pp. 901-911, 2006.

[61] T. Hayashi and T. P. Su, "Regulating ankyrin dynamics: roles of sigma-1 receptors," Proceedings of the National Academy of Sciences of the United States of America, vol. 98, no. 2, pp. 491496, 2001.

[62] T. Hayashi and T. P. Su, "Sigma-1 receptor chaperones at the ER- mitochondrion interface regulate $\mathrm{Ca}^{2+}$ signaling and cell survival," Cell, vol. 131, no. 3, pp. 596-610, 2007.

[63] T. P. Su, T. Hayashi, T. Maurice, S. Buch, and A. E. Ruoho, "The sigma-1 receptor chaperone as an inter-organelle signaling modulator," Trends in Pharmacological Sciences, vol. 31, no. 12, pp. 557-566, 2010.

[64] Z. Wu and W. D. Bowen, "Role of sigma-1 receptor C-terminal segment in inositol 1,4,5-trisphosphate receptor activation: constitutive enhancement of calcium signaling in MCF-7 tumor cells," Journal of Biological Chemistry, vol. 283, no. 42, pp. 28198-28215, 2008.

[65] T. Higo, M. Hattori, T. Nakamura, T. Natsume, T. Michikawa, and K. Mikoshiba, "Subtype-specific and ER lumenal environmentdependent regulation of inositol 1,4,5-trisphosphate receptor type 1 by ERp44," Cell, vol. 120, no. 1, pp. 85-98, 2005.

[66] L. M. John, J. D. Lechleiter, and P. Camacho, "Differential modulation of SERCA2 isoforms by calreticulin," Journal of Cell Biology, vol. 142, no. 4, pp. 963-973, 1998.

[67] H. L. Roderick, J. D. Lechleiter, and P. Camacho, "Cytosolic phosphorylation of calnexin controls intracellular $\mathrm{Ca}^{2+}$ oscillations via an interaction with SERCA2b," Journal of Cell Biology, vol. 149, no. 6, pp. 1235-1247, 2000.

[68] T. Simmen, J. E. Aslan, A. D. Blagoveshchenskaya et al., "PACS2 controls endoplasmic reticulum-mitochondria communication and Bid-mediated apoptosis," EMBO Journal, vol. 24, no. 4, pp. 717-729, 2005.

[69] M. R. Wieckowski, G. Szabadkai, M. Wasilewski, P. Pinton, J. Duszyński, and R. Rizzuto, "Overexpression of adenine nucleotide translocase reduces $\mathrm{Ca}^{2+}$ signal transmission between the ER and mitochondria," Biochemical and Biophysical Research Communications, vol. 348, no. 2, pp. 393-399, 2006.

[70] O. M. de Brito and L. Scorrano, "Mitofusin 2 tethers endoplasmic reticulum to mitochondria," Nature, vol. 456, no. 7222, pp. 605-610, 2008.

[71] M. R. M. R. Wieckowski, C. Giorgi, M. Lebiedzinska, J. Duszynski, and P. Pinton, "Isolation of mitochondria-associated membranes and mitochondria from animal tissues and cells," Nature Protocols, vol. 4, no. 11, pp. 1582-1590, 2009.

[72] D. de Stefani, A. Raffaello, E. Teardo, I. Szabó, and R. Rizzuto, "A forty-kilodalton protein of the inner membrane is the mitochondrial calcium uniporter," Nature, vol. 476, no. 7360, pp. 336-340, 2011.

[73] E. Rapizzi, P. Pinton, G. Szabadkai et al., "Recombinant expression of the voltage-dependent anion channel enhances the transfer of $\mathrm{Ca}^{2+}$ microdomains to mitochondria," Journal of Cell Biology, vol. 159, no. 4, pp. 613-624, 2002.

[74] C. Cárdenas, R. A. Miller, I. Smith et al., "Essential regulation of cell bioenergetics by constitutive InsP3 receptor $\mathrm{Ca}^{2+}$ 
transfer to mitochondria," Cell, vol. 142, no. 2, pp. 270-283, 2010.

[75] M. Høyer-Hansen, L. Bastholm, P. Szyniarowski et al., "Control of Macroautophagy by Calcium, Calmodulin-Dependent Kinase Kinase- $\beta$, and Bcl-2," Molecular Cell, vol. 25, no. 2, pp. 193-205, 2007.

[76] J. M. Vicencio, C. Ortiz, A. Criollo et al., "The inositol 1,4,5-trisphosphate receptor regulates autophagy through its interaction with Beclin 1," Cell Death and Differentiation, vol. 16, no. 7, pp. 1006-1017, 2009.

[77] J. M. Vicencio, S. Lavandero, and G. Szabadkai, " $\mathrm{Ca}^{2+}$, autophagy and protein degradation: thrown off balance in neurodegenerative disease," Cell Calcium, vol. 47, no. 2, pp. 112-121, 2010.

[78] A. Deniaud, O. Sharaf El Dein, E. Maillier et al., "Endoplasmic reticulum stress induces calcium-dependent permeability transition, mitochondrial outer membrane permeabilization and apoptosis," Oncogene, vol. 27, no. 3, pp. 285-299, 2008.

[79] S. Marchi, A. Rimessi, C. Giorgi et al., "Akt kinase reducing endoplasmic reticulum $\mathrm{Ca}^{2+}$ release protects cells from $\mathrm{Ca}^{2+}$ dependent apoptotic stimuli," Biochemical and Biophysical Research Communications, vol. 375, no. 4, pp. 501-505, 2008.

[80] R. Rizzuto, S. Marchi, M. Bonora et al., " $\mathrm{Ca}^{2+}$ transfer from the ER to mitochondria: when, how and why," Biochimica et Biophysica Acta, vol. 1787, no. 11, pp. 1342-1351, 2009.

[81] L. Scorrano, S. A. Oakes, J. T. Opferman et al., "BAX and BAK regulation of endoplasmic reticulum $\mathrm{Ca}^{2+}$ : a control point for apoptosis," Science, vol. 300, no. 5616, pp. 135-139, 2003.

[82] T. Szado, V. Vanderheyden, J. B. Parys et al., "Phosphorylation of inositol 1,4,5-trisphosphate receptors by protein kinase $\mathrm{B} / \mathrm{Akt}$ inhibits $\mathrm{Ca}^{2+}$ release and apoptosis," Proceedings of the National Academy of Sciences of the United States of America, vol. 105, no. 7, pp. 2427-2432, 2008.

[83] L. A. Voloboueva, M. Duan, Y. Ouyang, J. F. Emery, C. Stoy, and R. G. Giffard, "Overexpression of mitochondrial Hsp70/ Hsp75 protects astrocytes against ischemic injury in vitro," Journal of Cerebral Blood Flow and Metabolism, vol. 28, no. 5, pp. 1009-1016, 2008.

[84] J. A. Fishback, M. J. Robson, Y. T. Xu, and R. R. Matsumoto, "Sigma receptors: potential targets for a new class of antidepressant drug," Pharmacology and Therapeutics, vol. 127, no. 3, pp. 271-282, 2010.

[85] D. Fontanilla, M. Johannessen, A. R. Hajipour, N. V. Cozzi, M. B. Jackson, and A. E. Ruoho, "The hallucinogen N,Ndimethyltryptamine (DMT) is an endogenous sigma-1 receptor regulator," Science, vol. 323, no. 5916, pp. 934-937, 2009.

[86] T. Maurice and T. P. Su, "The pharmacology of sigma-1 receptors," Pharmacology and Therapeutics, vol. 124, no. 2, pp. 195-206, 2009.

[87] F. C. Sun, S. Wei, C. W. Li, Y. S. Chang, C. C. Chao, and Y. K. Lai, "Localization of GRP78 to mitochondria under the unfolded protein response," Biochemical Journal, vol. 396, no. 1, pp. 31-39, 2006.

[88] J. M. Baughman, F. Perocchi, H. S. Girgis et al., "Integrative genomics identifies MCU as an essential component of the mitochondrial calcium uniporter," Nature, vol. 476, no. 7360, pp. 341-345, 2011.

[89] F. Perocchi, V. M. Gohil, H. S. Girgis et al., "MICU1 encodes a mitochondrial EF hand protein required for $\mathrm{Ca}^{2+}$ uptake," Nature, vol. 467, no. 7313, pp. 291-296, 2010. 

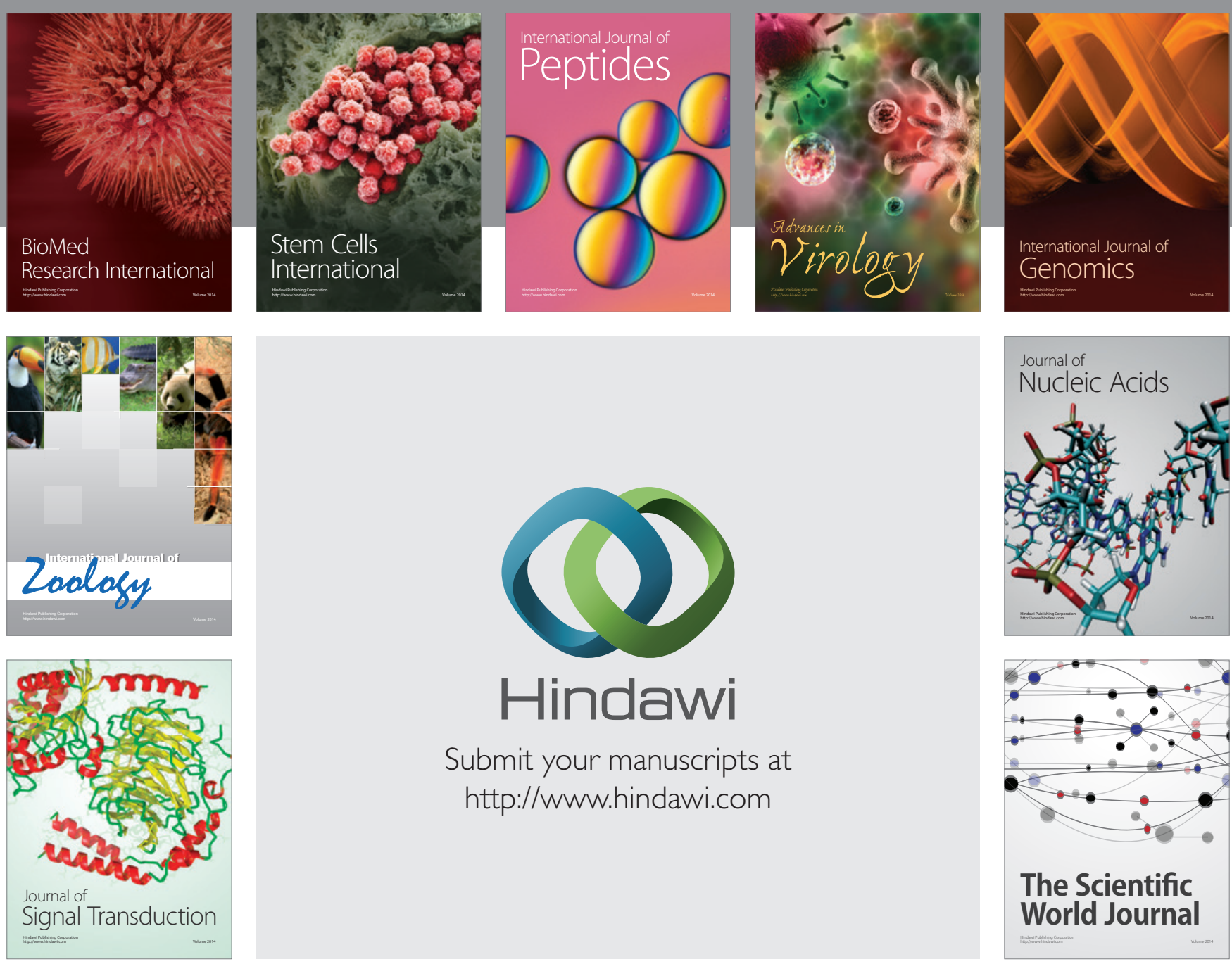

Submit your manuscripts at

http://www.hindawi.com
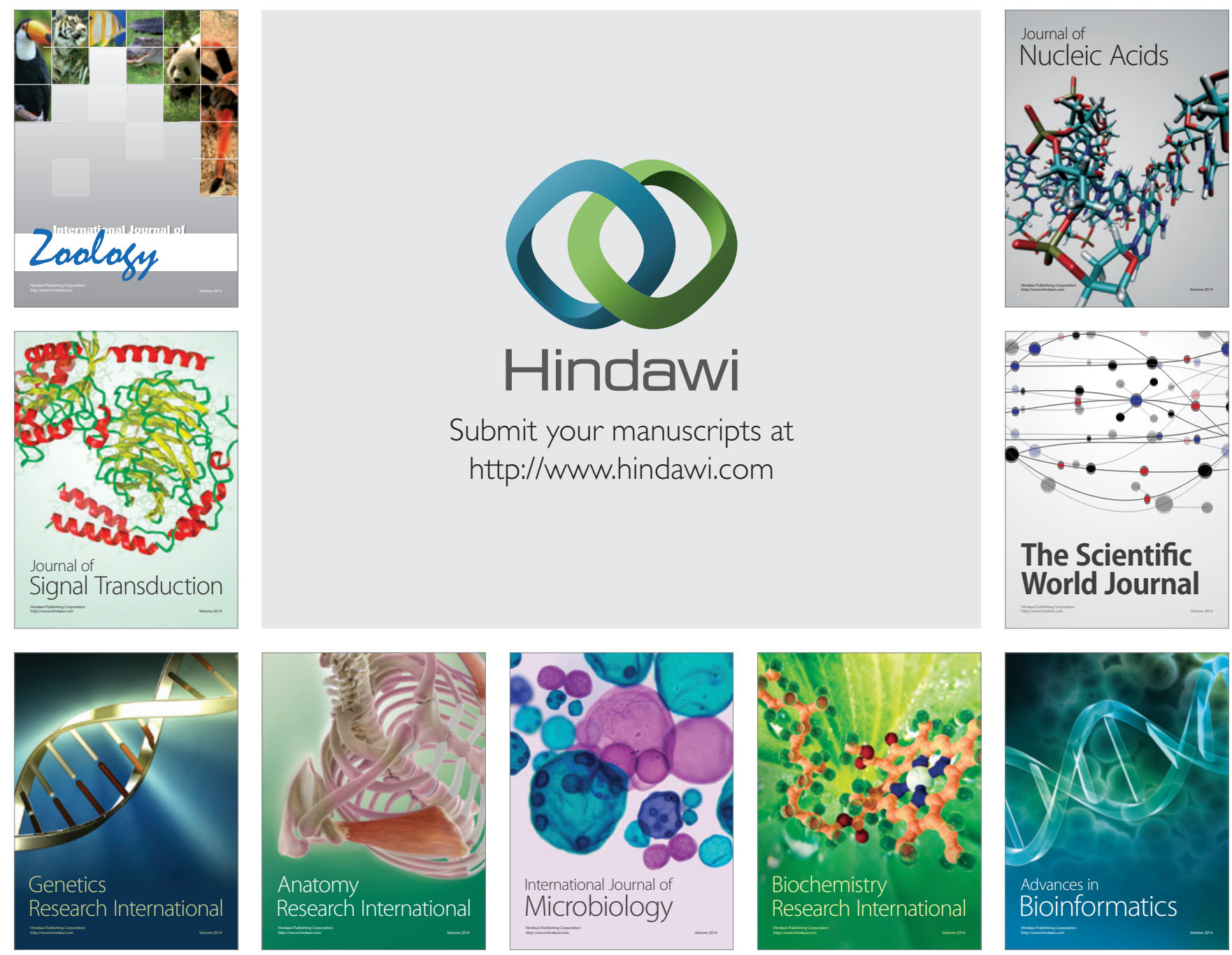

The Scientific World Journal
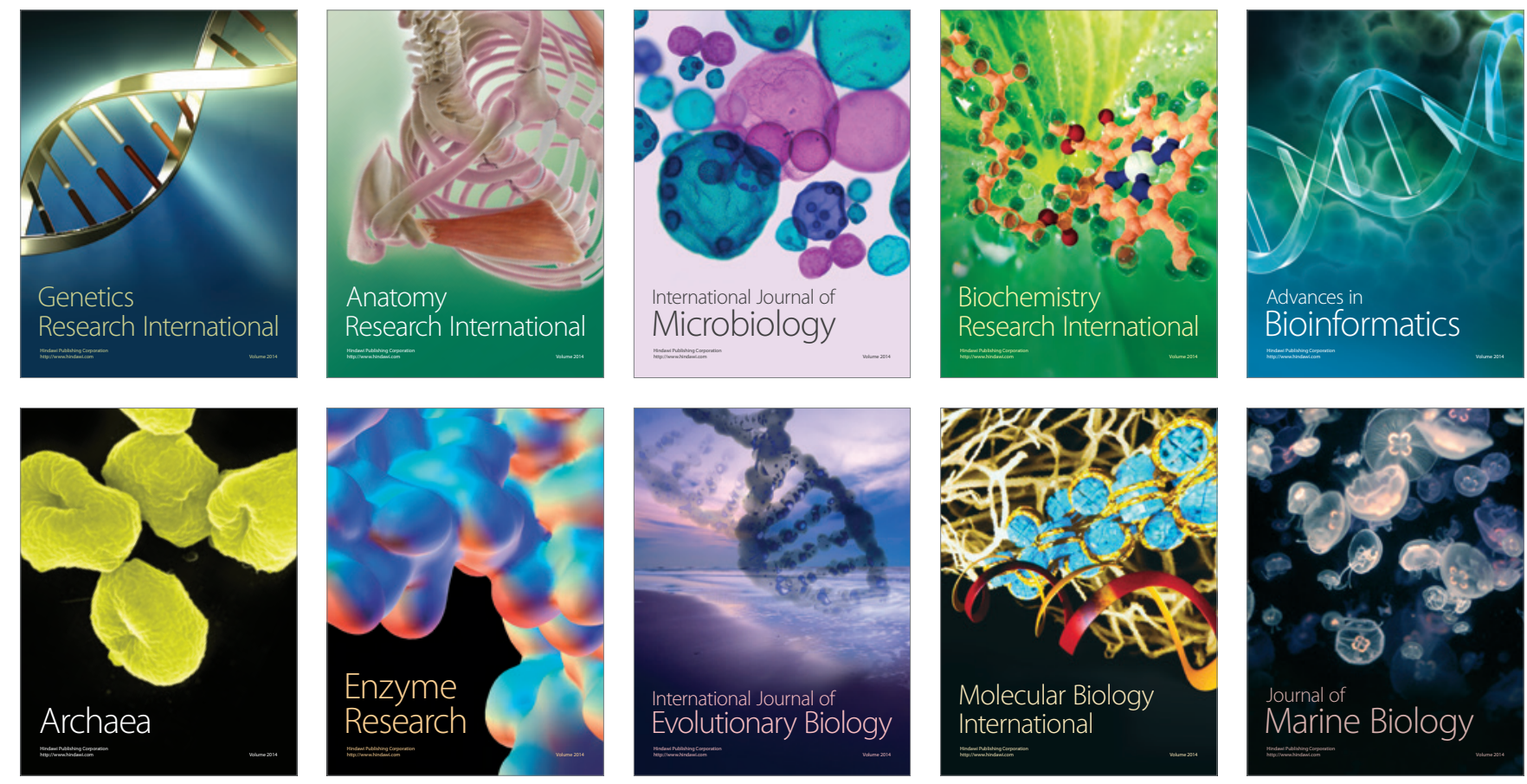